\title{
Influence of Different Clonal Material of the Variety Riesling (Vitis Vinifera L.) on the Mineral Composition of Leaves
}

\author{
Klaus SCHALLER \\ Geisenheim University, Department of Applied Biology, P.O.B. 1154, DE-65366 Geisenheim, Germany; \\ ${ }^{*}$ Corresponding author, e-mail: klaus.schaller@hs-gm.de
}

Bulletin UASVM Horticulture 72(1) / 2015

Print ISSN 1843-5254, Electronic ISSN 1843-5394

Doi:10.15835/buasvmcn-hort:10992

\begin{abstract}
Leaf analysis is a conventional system, which is commonly used to judge the nutritional status of perennial cultures. All plant parameters which may change the mineral composition of the tested plant part should be known in order to develop a correct rating matrix for fertilization recommendations. Perennials like grapevines have specifics which are unknown in annuals and which may have an influence on nutrient composition: rootstock, varieties, pruning and trellising systems and finally also clones selected out of varieties. Most of the varying factors are evaluated but no information exists about clonal material. In a field trial (7x7 lattice with 6 replicates) 5 of the most important 'Riesling' clones in Germany were planted and leaf composition was tested at three stages. The macro-nutrients $\mathrm{N}, \mathrm{Mg}$, and Ca were not influenced by the clone, whereas $\mathrm{P}$ and $\mathrm{K}$ showed a significant dependency from clonal material. The micro-nutrient showed with exception of Mn no influence of clones. Sampling time is significant for all nutrients except $\mathrm{Mg}$ and $\mathrm{Cu}$. There exist no interaction clone $\mathrm{x}$ sampling date. For the practice of leaf analysis it is important that the influence of clonal material is of minor importance. For phosphorus and potassium, both show a clonal dependency, a correction factor may be developed and used for the final judging of results.
\end{abstract}

Keywords: clonal material, components of variance, leaf analysis, macro, micro nutrients, 'Riesling'.

\section{INTRODUCTION}

Leaf composition is a central point in leaf analysis, which is often used in perennial cultures to determine their nutritional status and subsequent decisions for fertilization processes. Because leaf analysis is a conventional system it is therefore necessary to know all factors, which may have an influence on leaf composition.

Leaf analysis has a long history and its early beginnings are in the early 20th century (Atterberg, 1901; Lagatu and Maume, 1934; Lundegårdh, 1941; Goodall and Gregory, 1947). Walworth and Sumner (1987) introduced the DRIS-system, which was formerly developed and improved by Beaufils (1957, 1973). Parent et al. $(1992,1994)$ further corrected some pitfalls and enhanced the mathematical basis of this evaluation system. In contrast to annuals grapevines show a distinct differentiation between varieties, which may have an influence on nutrient composition. Additional influences come from differing rootstocks, which may also act on nutrient uptake pattern (Esmail Fallahi et al. 2005; Cook and Lider, 1964; Downton, 1977).

More recently Benito et al. (2013) published a comprehensive work comparing blade and petiole analysis at different developmental stages of Garnacha tinta. Blade as well as petioles are suited analyzing for different nutrients and phenological stages. 
It is a well known fact that improvements in viticulture, e.g. yields and qualities are results of clonal selection of the primary varietal material (Schmid et al., 2011). But in contrary there exist no reports about changes in mineral composition of those clonal materials.

\section{MATERIALS AND METHODS}

Test plots and soil conditions

The vineyard is located at the "State Estate Farm Steinberg" (50²'3,4" N , 8 3' 9,2" E). Soil developed from devonian slate material, medium to deeply weathered. In some parts of the test plot it is mixed with colluvial material. Inclination is 30-35\%. Soil fertility level: medium-good water holding capacity; soil nutrients $\mathrm{P}, \mathrm{K}, \mathrm{Mg}$ are high and soil pH ranges from 6.2-6.8.

Plant material

Selected Riesling clones. Clone 237 Gm, $198 \mathrm{Gm}, 239 \mathrm{Gm}$ and Steinberg $88 \mathrm{Gm}$ all from the Department of Grapevine Breeding of the University Geisenheim and clone 21 Bullay from the Viticulture extension Centre Trier. All clones were grafted on rootstock $5 \mathrm{C}$, clone $6 \mathrm{Gm}$.

Cultivation and leaf sampling

Planting density was 5700 plants/ha with a stem height of $0.75 \mathrm{~m}$. Training system was one flat bow with a bud load of $8 \mathrm{bud} / \mathrm{m}^{2}$. Leaves were sampled according to Lévy (1967) at three stages: 1. Full bloom-after boom ( $80 \%$ of flowers shed); 2. veraison; 3 . ripeness $\left(\geq 60^{\circ} \mathrm{Oe} / \geq 14.7^{\circ} \mathrm{Brix}\right)$. Leaves were separated in blades and petioles. Blades were processed for further analysis. The test was arranged in a $7 \times 7$ lattice.

Analysis and statistical methods

The dried plant material was milled and wet ashed (Schaller 2000). N and P were determined by Flow Injection Analysis (FIA) (Schaller et al. 1988); K and Ca by flame photometry, Mg, Fe, Mn, $\mathrm{Zn}$, and $\mathrm{Cu}$ by Atomic Absorption Spectroscopy (AAS). Results were expressed on dry matter basis.

Statistical analysis was done with one and two way ANOVA with following LSD-tests. In addition a "Multiple Regression Analysis" was made in order to find relationships between leaf composition and yield respectively must density.

\section{RESULTS AND DISCUSSIONS}

Leaf composition at stage "full bloom-after boom" is given in table 1 . This stage is very important for the annual life cycle of grapevines because future yield and quality are determined by a successful flowering and fertilization process. The macro-nutrients $\mathrm{N}, \mathrm{K}$ and $\mathrm{Mg}$ are

Tab. 1.Content of macro-nutrients $\mathrm{N}, \mathrm{P}, \mathrm{K}, \mathrm{Mg}$, and Ca (\% d.m.) in leaves of different 'Riesling' clones at stage "full bloom - after bloom" (80\% of flowers shed)

\begin{tabular}{cccccc}
\hline Clone & $\mathrm{N}$ & $\mathrm{P}$ & $\mathrm{K}$ & $\mathrm{Mg}$ & $\mathrm{Ca}$ \\
\hline $237 \mathrm{Gm}$ & $2,94 \mathrm{a}$ & $0,483 \mathrm{a}$ & $1,50 \mathrm{a}$ & $0,148 \mathrm{a}$ & $2,02 \mathrm{a}$ \\
\hline $198 \mathrm{Gm}$ & $2,86 \mathrm{a}$ & $0,357 \mathrm{ac}$ & $1,44 \mathrm{a}$ & $0,145 \mathrm{a}$ & $2,14 \mathrm{ac}$ \\
\hline $239 \mathrm{Gm}$ & $2,95 \mathrm{a}$ & $0,367 \mathrm{ac}$ & $1,45 \mathrm{a}$ & $0,147 \mathrm{a}$ & $2,05 \mathrm{ac}$ \\
\hline st 99 & $2,87 \mathrm{a}$ & $0,365 \mathrm{ac}$ & $1,51 \mathrm{a}$ & $0,142 \mathrm{a}$ & $1,93 \mathrm{ac}$ \\
\hline $21 \mathrm{~B}$ & $2,80 \mathrm{a}$ & $0,268 \mathrm{bc}$ & $1,35 \mathrm{a}$ & $0,152 \mathrm{a}$ & $1,77 \mathrm{bc}$ \\
\hline
\end{tabular}

Note: Different letters between cultivars denote significant differences (LSD test, $\mathrm{P}<0.05$ ).

Tab. 2. Content of macro-nutrients N, P, K, Mg, and Ca (\% d.m.) in leaves of different 'Riesling' clones at stage "veraison"

\begin{tabular}{cccccc}
\hline Clone & $\mathrm{N}$ & $\mathrm{P}$ & $\mathrm{K}$ & $\mathrm{Mg}$ & $\mathrm{Ca}$ \\
\hline $237 \mathrm{Gm}$ & $2,15 \mathrm{a}$ & $0,372 \mathrm{a}$ & $1,85 \mathrm{a}$ & $0,157 \mathrm{ac}$ & $2,91 \mathrm{ac}$ \\
\hline $198 \mathrm{Gm}$ & $2,13 \mathrm{a}$ & $0,272 \mathrm{bd}$ & $1,64 \mathrm{bd}$ & $0,157 \mathrm{ac}$ & $3,15 \mathrm{ac}$ \\
\hline $239 \mathrm{Gm}$ & $2,14 \mathrm{a}$ & $0,277 \mathrm{ad}$ & $1,73 \mathrm{ad}$ & $0,153 \mathrm{ac}$ & $2,99 \mathrm{ac}$ \\
\hline st 99 & $2,07 \mathrm{a}$ & $0,283 \mathrm{ad}$ & $1,76 \mathrm{ad}$ & $0,148 \mathrm{a}$ & $2,60 \mathrm{~b}$ \\
\hline $21 \mathrm{~B}$ & $2,10 \mathrm{a}$ & $0,203 \mathrm{~cd}$ & $1,60 \mathrm{~cd}$ & $0,168 \mathrm{~b}$ & $2,94 \mathrm{ac}$ \\
\hline
\end{tabular}

Note: Different letters between cultivars denote significant differences (LSD test, $\mathrm{P}<0.05$ ). 
not influenced by the clone. With $\mathrm{P}$ there is a significant difference between clone $237 \mathrm{Gm}$ and clone $21 \mathrm{~B}$. The Geisenheim clones $(237 \mathrm{Gm}$ - st 99) are homogenous and show no differences.

The same result applies for $\mathrm{Ca}$, where 237 Gm and $21 \mathrm{~B}$ differ significantly. The values for all macros match very well with those proposed by Failla et al. (1993).

Also an important stage of grapevine development is "veraison" (table 2). During that stage plant physiological processes are changed from a more vegetative pronounced towards an accentuated generative growth. Also, important compounds necessary for fruit develop-ment are relocated in growing fruits, e.g. nitrogen and potassium as a co-transporter for sugars. As already seen for the stage "full bloom-after bloom" also at stage "veraison" $\mathrm{N}$ shows no significant differences between all tested clones.

$\mathrm{P}$ is highest in $237 \mathrm{Gm}$ whereas $21 \mathrm{~B}$ shows lowest value. Potassium is highest in all $\mathrm{Gm}$ selections, 21 B significant lower. Also a negative interaction between $\mathrm{K}$ and $\mathrm{Mg}$ in all clones can be seen. For Ca only st 99 shows a significant lower concentration. All the values are in accordance with that proposed by Failla et al. (1993).
The mineral composition of leaves at the stage of "ripening" is quite homogenous (table 3). N, $\mathrm{Mg}$ and $\mathrm{Ca}$ are not different between the diverse clones. Concerning $\mathrm{P}$ the same pattern as at stage "bloom" exists: $21 \mathrm{~B}$ is significantly lower than all other $\mathrm{Gm}$ clones. Same is also true for $\mathrm{K}$ but in the $\mathrm{Gm}$ group $237 \mathrm{Gm}, 198 \mathrm{Gm}$ and st 99 differ significantly. Up to now the values determined at "ripening" are discussed controversially, because their explanatory power as indicator for a possible fertilization is highly controversial.

The composition of micro-nutrients $\mathrm{Fe}, \mathrm{Zn}$, $\mathrm{Mn}$ and $\mathrm{Cu}$ is demonstrated in the following tables 4-6 for the differing developmental stages.

Table 4 shows the micro-nutrient contents at stage "full bloom" for $\mathrm{Fe}, \mathrm{Zn}, \mathrm{Mn}$, and $\mathrm{Cu}$. For all micros no significant differences could be detected. The measured values for $\mathrm{Zn}$ and $\mathrm{Cu}$ seem to be optimal. Fe and $\mathrm{Mn}$ are quite high. This may result from soil $\mathrm{pH}$, which is in a range where solubility in soil solution is extremely good.

In table 5 micro-nutrient concentrations during stage of "veraison" are demonstrated. For $\mathrm{Zn}$ and $\mathrm{Mn}$ there exist no significant differences for all 'Riesling' clones. In comparison to stage of "bloom" these values increased also significantly. Fe content in $\mathrm{Gm}$ clones did not differ; $21 \mathrm{~B}$ was

Tab. 3. Content of macro-nutrients $\mathrm{N}, \mathrm{P}, \mathrm{K}, \mathrm{Mg}$, and $\mathrm{Ca}(\% \mathrm{~d}$.m.) in leaves of different 'Riesling' clones at stage "ripeness" $\left(>60^{\circ} \mathrm{Oe} / 14,6^{\circ} \mathrm{Brix}\right)$

\begin{tabular}{cccccc}
\hline Clone & $\mathrm{N}$ & $\mathrm{P}$ & $\mathrm{K}$ & $\mathrm{Mg}$ & $\mathrm{Ca}$ \\
\hline $237 \mathrm{Gm}$ & $1,110 \mathrm{a}$ & $0,377 \mathrm{a}$ & $1,63 \mathrm{a}$ & $0,265 \mathrm{a}$ & $3,03 \mathrm{a}$ \\
\hline $198 \mathrm{Gm}$ & $0,993 \mathrm{a}$ & $0,235 \mathrm{ac}$ & $1,31 \mathrm{bf}$ & $0,265 \mathrm{a}$ & $2,91 \mathrm{a}$ \\
\hline $239 \mathrm{Gm}$ & $1,080 \mathrm{a}$ & $0,277 \mathrm{ac}$ & $1,28 \mathrm{cf}$ & $0,277 \mathrm{a}$ & $3,38 \mathrm{a}$ \\
\hline st 99 & $0,997 \mathrm{a}$ & $0,288 \mathrm{ac}$ & $1,34 \mathrm{df}$ & $0,268 \mathrm{a}$ & $3,21 \mathrm{a}$ \\
\hline $21 \mathrm{~B}$ & $1,120 \mathrm{a}$ & $0,153 \mathrm{bc}$ & $1,14 \mathrm{ef}$ & $0,290 \mathrm{a}$ & $2,86 \mathrm{a}$ \\
\hline
\end{tabular}

Note: Different letters between cultivars denote significant differences (LSD test, $\mathrm{P}<0.05$ ).

Tab. 4. Content of micro-nutrients $\mathrm{Fe}, \mathrm{Zn}, \mathrm{Mn}$, and $\mathrm{Cu}(\mathrm{mg} / \mathrm{kg} \mathrm{d.m.)} \mathrm{in} \mathrm{leaves} \mathrm{of} \mathrm{different} \mathrm{'Riesling'}$ clones at stage "full bloom - after bloom" ( $80 \%$ of flowers shed)

\begin{tabular}{ccccc}
\hline Clone & Fe & Zn & Mn & Cu \\
\hline $237 \mathrm{Gm}$ & $269 \mathrm{a}$ & $95 \mathrm{a}$ & $169 \mathrm{a}$ & $10 \mathrm{a}$ \\
\hline $198 \mathrm{Gm}$ & $289 \mathrm{a}$ & $96 \mathrm{a}$ & $211 \mathrm{a}$ & $8 \mathrm{a}$ \\
\hline $239 \mathrm{Gm}$ & $274 \mathrm{a}$ & $104 \mathrm{a}$ & $189 \mathrm{a}$ & $9 \mathrm{a}$ \\
\hline st 99 & $287 \mathrm{a}$ & $101 \mathrm{a}$ & $199 \mathrm{a}$ & $8 \mathrm{a}$ \\
\hline $21 \mathrm{~B}$ & $258 \mathrm{a}$ & $96 \mathrm{a}$ & $231 \mathrm{a}$ & $8 \mathrm{a}$ \\
\hline
\end{tabular}

Note: Different letters between cultivars denote significant differences (LSD test, $\mathrm{P}<0.05$ ). 
significantly different. There was also an increase compared to "bloom". Cu content varied a little bit but in comparison to "bloom" was only a negligible drift.

Table 6 describes the micronutrient contents in leaves of different 'Riesling' clones at stage "ripeness". $\mathrm{Fe}, \mathrm{Zn}$ and $\mathrm{Cu}$ concentrations show no significant differences between clones. With exception of $\mathrm{Cu}$ a steady increase of all other micros from "bloom" to "ripeness is observed. Mn concentrations in $\mathrm{Gm}$ clones do not differ, only 21 $\mathrm{B}$ has an exceptional high content at this stage. It is possible that an exogenous contamination occurred.

By means of a two way ANOVA the influences of clonal material, sampling date of leaves and the interaction of "clone $\mathrm{x}$ sampling date" were evaluated. The results are shown in fig. 1 . The total occurring variance was broken down on "clone", "date", "clone $\mathrm{x}$ date" and the unexplained "error".

The nutrients P. K. and $\mathrm{Mn}$ are influenced significantly by clones. The part of total variance amounts to $24 \%$ for P, $13 \%$ for $\mathrm{K}$ and $10 \%$ for Mn. Maybe that these figures can serve as correction factors during the judging procedure of leaf analysis as a tool for fertilizer recommendations.
Important, that $\mathrm{N}$ as the driving force for plant growth shows no clonal influence; only $0.2 \%$ of the total variance is shared with clone.

Sampling date is most influential on leaf composition: $11 \%(\mathrm{P})$ to $96 \%(\mathrm{~N})$ of total variance is pooled in that source of variance. Most shares are highly significant, e.g. "sampling date" has to be considered in every case in a leaf analysis system.

There are no influences from interactions (date $\mathrm{x}$ clone). This finding is important for leaf analysis, because in case of significance it would really complicate the system.

One important goal of leaf analysis is to evaluate if the leaf mineral nutrient contents are sufficient for an optimal yield formation and in case of grapevines also for high sugar accumulation in berries. The latter is necessary for the production of agreeable and high quality wines.

In order to show the influence of different leaf nutrients, multiple regression analysis (MRA) were carried out. Dependent variables were yield/vine (kg/vine) and must density $\left({ }^{\circ} \mathrm{Oe}\right)$; independent variables: macro and micro-nutrients in leaves. The calculations were made with the complete data set and without consideration of clones, e.g. 30 replications.

Tab. 5. Content of micro-nutrients $\mathrm{Fe}, \mathrm{Zn}, \mathrm{Mn}$, and $\mathrm{Cu}(\mathrm{mg} / \mathrm{kg} \mathrm{d.m.)} \mathrm{in} \mathrm{leaves} \mathrm{of} \mathrm{different} \mathrm{'Riesling'}$ clones at stage "veraison"

\begin{tabular}{ccccc}
\hline Clone & Fe & Zn & Mn & Cu \\
\hline $237 \mathrm{Gm}$ & $322 \mathrm{a}$ & $165 \mathrm{a}$ & $186 \mathrm{a}$ & $14 \mathrm{a}$ \\
\hline $198 \mathrm{Gm}$ & $271 \mathrm{abc}$ & $160 \mathrm{a}$ & $241 \mathrm{a}$ & $9 \mathrm{ab}$ \\
\hline $239 \mathrm{Gm}$ & $302 \mathrm{ab}$ & $180 \mathrm{a}$ & $230 \mathrm{a}$ & $10 \mathrm{ab}$ \\
\hline st 99 & $306 \mathrm{abc}$ & $186 \mathrm{a}$ & $269 \mathrm{a}$ & $7 \mathrm{~b}$ \\
\hline $21 \mathrm{~B}$ & $275 \mathrm{~b}$ & $159 \mathrm{a}$ & $271 \mathrm{a}$ & $7 \mathrm{~b}$ \\
\hline
\end{tabular}

Note: Different letters between cultivars denote significant differences (LSD test, $\mathrm{P}<0.05$ ).

Tab. 6. Content of micro-nutrients $\mathrm{Fe}, \mathrm{Zn}, \mathrm{Mn}$, and $\mathrm{Cu}(\mathrm{mg} / \mathrm{kg} \mathrm{d.m}$.) in leaves of different 'Riesling' clones at stage "ripeness" $\left(>60^{\circ} \mathrm{Oe} / 14,6^{\circ} \mathrm{Brix}\right)$

\begin{tabular}{ccccc}
\hline Clone & Fe & Zn & Mn & Cu \\
\hline $237 \mathrm{Gm}$ & $319 \mathrm{a}$ & $214 \mathrm{a}$ & $223 \mathrm{a}$ & $7 \mathrm{a}$ \\
\hline $198 \mathrm{Gm}$ & $316 \mathrm{a}$ & $211 \mathrm{a}$ & $325 \mathrm{ab}$ & $9 \mathrm{a}$ \\
\hline $239 \mathrm{Gm}$ & $309 \mathrm{a}$ & $207 \mathrm{a}$ & $293 \mathrm{ab}$ & $8 \mathrm{a}$ \\
\hline st 99 & $327 \mathrm{a}$ & $225 \mathrm{a}$ & $269 \mathrm{ab}$ & $9 \mathrm{a}$ \\
\hline $21 \mathrm{~B}$ & $296 \mathrm{a}$ & $206 \mathrm{a}$ & $390 \mathrm{~b}$ & $8 \mathrm{a}$ \\
\hline
\end{tabular}

Note: Different letters between cultivars denote significant differences (LSD test, $\mathrm{P}<0.05$ ). 
The data set for "leaf composition at full bloom" and its influence on upcoming yield and must density resulted in two equations:

(1) yield (kg/vine) $=1,840-0,462 \times \mathrm{K} \%-0,126 \times$ N\% - 0,439 x P\% [R $\left.{ }^{2} \times 100=30,2 \%\right]$

(2) ${ }^{\circ} \mathrm{Oe}=64,127+13,873 \times \mathrm{N} \%+1,766 \times \mathrm{K} \%+$ $6,225 \times \mathrm{P} \%\left[\mathrm{R}^{2} \times 100=23,7 \%\right]$

For the formation of yield at this early stage of plant development $\mathrm{K}$ is most important. There is a negative relationship with a partial $\mathrm{R}^{2}$ of $26,1 \%$; $\mathrm{N}$ and $\mathrm{P}$ overtake only $4,1 \%$ of the explanation of the yield factor.

Equation 2 describes the future formation of must density and in that case $\mathrm{N}$ is the most important factor explaining 21,3\% of the variation of must density. $\mathrm{K}$ and $\mathrm{P}$ are only responsible for $2,4 \%$ explanation. That means yield and must density is not interdependent and fertilization has to look for an optimum!

Calculating upcoming yield and must density with the second data set "veraison" the following equations could be achieved:

(1) yield (kg/vine) $=2,949-0,638 \times \mathrm{N} \%-0,407 \times$ $\mathrm{K} \%-0,888 \times \mathrm{P} \%\left[\mathrm{R}^{2} \mathrm{x} 100=40,3 \%\right]$
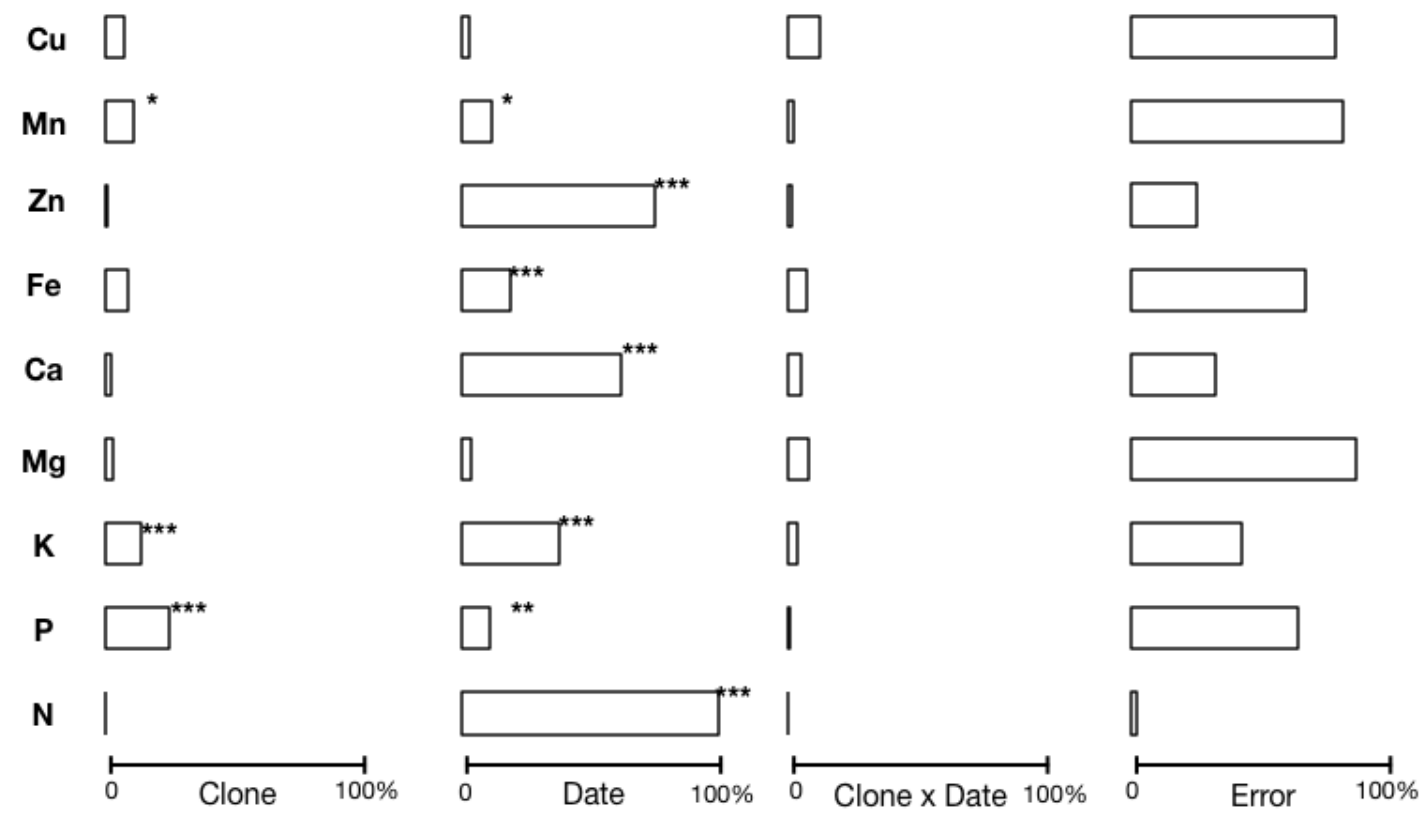

Fig.1. Breakdown of total variance for mineral nutrients in grapevine leaves and their partitioning on clone, date of leaf sampling, interaction clone $\mathrm{x}$ date, and unexplained variance (\%) .
(2) ${ }^{\circ} \mathrm{Oe}=73,935+17,023 \times \mathrm{K} \%+2,742 \times \mathrm{N} \%$ $\left[\mathrm{R}^{2} \mathrm{x} 100=27,4 \%\right]$

At this stage of development all important macro elements are negatively correlated with the yield formation process (Eq.1). N overtakes 10,8\%, $\mathrm{K} 20,7 \%$ and $\mathrm{P}$ 8,5\% explanation of future yield respectively. Too much $\mathrm{N}$ at this stage increases the risk fungus diseases and higher amounts of $\mathrm{K}$ are an indicator that physiological disorders have an influence on yields.

Must density (Eq. 2) is more or less a function of $\mathrm{K}$ in leaves; $\mathrm{N}$ is an absolutely minor factor. Already is demonstrated that the nutrients $\mathrm{N}$ and $\mathrm{K}$ and to a lesser extend $\mathrm{P}$ have an outstanding influence on both quality indicators yield and must density. And again it can be seen that both are coupled quite strong together. High yield results in low must density and vice versa. In contrast to former believes that an intensification with a high fertilizer input it is possible to switch off these rules, one can now see physiological principles cannot be overcome.

\section{CONCLUSION}

Leaf analysis is mainly used for perennials, because these plantations are established on a field for a longer period of time, e.g. 20-40 years 
in the case of grapevines. In contrast to annuals which move every year from one field to another the process of soil testing and fertilization is more complicated and not in every case constructive. Above all grapevines have a rooting system which exploits soils down to $1 \mathrm{~m}$ and deeper. Therefore analysing the plant or parts from it is more promising than soil testing with a lot of uncertainties. But plant analysis as well as soil testing has pitfalls which should be realised. Leaf analysis can be a very useful tool for fertilizer recommendation in perennial plantings but it is necessary to standardise the procedure in order to develop reliable recommendations for the growers.

Because the approach is as conventional as in soil testing it is necessary to figure out all sources of variation to reduce possible errors. Concerning the plant, endogenous as well as exogenous sources have to be taken into consideration. A part of them have been already evaluated: variety, rootstock, training system, bud load, plant part, sampling time, soil tillage etc. In viticulture more or less old and traditional varieties are used for quality wine production. Improvements concerning yield and quality are achieved with clonal material, which will be obtained by active selection. Therefore this may be a further source of variation.

In a field test with 5 'Riesling' clones (main types in Germany) in a 7x7 lattice with 6 replicates it was found out that clonal material has only a small to negligible effect on the leaves' nutrient composition. Therefore clones need not to be considered in leaf analysis. In a further MRA analysis it was possible to demonstrate the strong interdependencies of nutrients and their influence on yielding and quality formation.

\section{REFERENCES}

1. Atterberg A (1901). Die Variation des Nährstoffgehaltes beim Hafer. Journal für Landwirtschaft 49:97-172.

2. Benito A, Romero I, Dominguez N, Garcia-Escudero E and Martin I (2013). Leaf blade and petiole analysis for nutrient diagnosis in Vitis vinifera L. cv. Garnacha tinto. Austr. J. Grape Wine Res. 19:285-298.

3. Beaufils ER (1957). Research for rational exploitation of Hevea using a physiologic diagnosis based on the mineral analysis of various parts of the plants. Fertilite 3:27-38.
4. Beaufils ER (1973). Diagnosis and Recommendation Integrated System (DRIS): A General scheme for Experimentation and Calibration based on Principles Developed From Research in Plant Nutrition. University of Natal, Soil Science Bulletin 1.

5. Cook JA and Lider LA (1964). Mineral composition of blooming grape petiole in relation to rootstock and scion variety behavior. Proc. Amer. Soc. Hort. Sci. 84:243-254.

6. Downton WJ (1977). Influence of rootstocks on the accumulation of chloride, sodium and potassium in grape vines. Austral. J. Agr. Res. 28:879-889.

7. Fallahi E, Shafii B, Stark JC, Fallahi B and Hafez JC (2005). Influence of Wine Grape Cultivars on Growth and Leaf Blade and Petiole Mineral Nutrients. HortTechnology 15(4):825-830.

8. Failla O, Stringari G, Porro D and Scienza A (1993). Determination of leaf standards for apple trees and grapevines in northern Italy. Optimization of Plant Nutrition, 37-41.In: Developments in Plant and Soil Science Vol. 53. Kluwer Academic Publishers.

9. Goodall DW and Gregory FG (1947). Chemical Composition of Plants as an Index of Their Nutritional Status. Imperial Bureau Horticulture and Plantation Crops. Technical Communication 17.

10. Lagatu H and Maume L(1934). Recherche par la diagnostic foliaire de l'équilibre optimum d'alimentation NPK chez une plante cultivée. Comptes Rendus Hebdomanaires des Séances de l'Academie d'Agricultures de France 20:631644.

11. Lévy JF (1967). L'application du diagnostic foliaire à la determination des besoins alimentation des vignes. Vignes et Vins 157:23-31.

12. Lundegårdh H (1941). Die Tripelanalyse. Theoretische und praktische Grundlagen einer pflanzenphysiologischen Methode zur Bestimmung des Düngerbedürnisses des Ackerbodens. Lantbrukshögskolans Annaler 9:127-221.

13. Parent L.E. and M. Dafir. (1992). A theoretical Concept of Compositional Nutrient Diagnosis. J. Americ. Soc. Hort. Sci. 117(2):239-242

14. Parent, LE, Isfan D, Trembley N, Karam A. (1994). Multivariate nutrient diagnosis of carrot crop. J. Amer. Soc. Hort. Sci. 119(3):420-426.

15. Schaller K, Lehnart R, Weber V and Euler C. (1988). Fließinjektionsanalyse in der Bodenuntersuchung und Pflanzenanalyse. Fresenius Z. Anal. Chemie 329:701-706.

16. Schaller K (2000). Praktikum zur Bodenkunde und Pflanzenernährung. Geisenheimer Berichte Nr. 2. 8. Auflage. ISBN 3-934742-01-7.

17. Schmid J, Manty F, Lindner B. (2011). Geisenheimer Rebsorten und Klone. Geisenheimer Berichte 67. 2nd ed. Geisenheim.

18. 18. Walworth JL and Sumner ME. (1987). The Diagnosis and Recommendation Integrated System (DRIS). Advances in Soil Science 8:149-188. 